\title{
Special Interest Groups, Public Policy and Social Welfare
}

\author{
Tetsuro Okazaki
}

\begin{abstract}
In this paper, we examine the amount of goods provided by the government using common agency models. It has already been proved that the public policy is efficient in the truthful equilibrium. But, this efficiency reflects only welfare of the agent and the principals who make lobbying activities. Therefore, if there is some principal who does not make lobbying activity, the public policy can be inefficient from the viewpoint of the social welfare. In this paper, focusing on this point, we analyze public policy decision. Especially, we prove that the amount of goods provided by the government is greater than that in the efficient allocation if some group does not make lobbying activity. Moreover, we prove that the partial prohibition against lobby enlarges the government size in some cases. In addition, if the groups' valuation for the good increases, then the allocation becomes to be more inefficient, and if the marginal cost decreases, then the allocation also becomes to be more inefficient. Last, based on these results, an interpretation of the success and failure of Japanese industrial policy is presented.
\end{abstract}

Index Terms-Common agency, efficiency of public policy, industrial policy in Japan, special interest groups.

\section{INTRODUCTION}

There are many studies that examine relation between special interest groups and public policy decision. In many of these studies, common agency models are adopted (see, for example [1]-[8]). In the common agency models, there are one agent who decides an action and many principals who are affected by this decision and try to influence the agent's decision. In the studies of public policy, in general, a government is viewed as the agent and special interest groups are viewed as the principals. The government decides public policy that affects the special interest groups and the groups make lobbying activities.

In this paper, we examine the amount of goods provided by the government using common agency models. In order to provide the goods, the government has to impose taxation on individuals. So the size of government can be measured by the amount of goods provided by the government. Thus, through the examination, we investigate the size of the government.

In particular, we consider the following societies. There are many groups and group-specific goods. These goods are provided by the government. Each group's utility is affected by the amount of the group-specific good. The cost to provide the good is financed by taxation that is imposed on every group. So each group wants the provision of the good to be favorable for him. Therefore some groups try to organize interest groups lobbying for the provision of the goods by the government. In order to examine relation

Manuscript received October 5, 2012; revised December 11, 2012.

Tetsuro Okazaki is with Chiba University of Commerce (e-mail: t2okaza@cuc.ac.jp). between lobbying activities and the amount of public goods, we adopt common agency models.

In general, common agency models have multiple subgame perfect equilibria (see [2]). One class of equilibria, called truthful equilibria, has been identified by [2]. The truthful equilibria have many appealing characteristics and seem to be focal point. This is especially because each principle's truthful strategy is in the set of her best response strategies for any set of strategies of the other principals. So, each principal bears essentially no cost from playing a truthful strategy, no matter what she expects as for the other principals' strategies. Therefore, many studies after [2] assume that truthful equilibria realize and analyze the property of the truthful equilibria.

The truthful equilibria have many desirable properties in addition to the point mentioned above. Especially, the action by the agent in the truthful equilibrium is efficient. In the studies of public policy, it has already been proved that the public policy is efficient in the truthful equilibrium of the common agency models (see [2], [4]). This is also true in the case of the allocation of goods provided by the government (see [8]).

But, this efficiency reflects only welfare of the agent and the principals who make lobbying activities. Therefore, if there is some principal who does not make lobbying activity, the public policy can be inefficient from the viewpoint of the social welfare. In this paper, focusing on this point, we analyze public policy decision.

Moreover, based on the results of our analysis, an interpretation of the success and failure of Japanese industrial policy after the Second World War is presented. Japanese industrial policy has gotten much attention because of Japanese economic success after the Second World War. Our interpretation sheds a new light on the study of Japanese industrial policy.

\section{THE MODEL}

We consider societies with a government and $n$ groups. The public policy is $x=\left(x_{1}, \ldots, x_{n}\right)$ and $t=\left(t_{1}, \ldots, t_{n}\right)$. In this policy, $x_{i}$ that affects the group $i$ 's utility is the level of group-specific good provided by the government and $t_{i}$ is tax imposed on group $i$. Some groups can make lobbying activity in order to implement the policy that is favorable for them.

In order to analyze such situations, we adopt common agency models. That is, there is an agent and $n$ principals. Here, the agent is the government and the principals are the groups.

The set of principals is $\{1, \ldots, n\}$. This represents the set of groups affected by public policy. We denote the set of special interest group by $L$ with $L \subset\{1, \ldots, n\}$. This means that each group in $L$ makes lobbying activity. Let the 
cardinality of $L$ be $l$. The principal $i(i \in\{1, \ldots, n\})$ has her own utility function:

$$
U_{i}\left(x_{i}, y_{i}\right)=u_{i}\left(x_{i}\right)+y_{i}=a x_{i}^{0.5}+y_{i}
$$

where $y_{i}$ is consumption level of the private good. Each principal has her income $I_{i}$. This is measured by the level of private good. Let $=\sum_{i=1}^{n} I_{i}$.

We define $T$ by $T=\sum_{i=1}^{n} T_{i}$ and assume that $T$ has to be equal to the cost of producing $\left(x_{1}, \ldots, x_{n}\right)$. For simplicity, let

$$
T=b \sum x_{i}
$$

Under this technology, the marginal and average costs are $b$ for any $x_{i}$. As for tax system, we consider the case where $t_{i}=T / n$ for any $i$. (If tax system is freely determined by the government who is under influence of the lobbying activities, $\sum_{i \notin L} t_{i}=T$ should hold in equilibrium.)

In order to represent lobbying activities, we assume that each principal makes payment to the agent. Principal $i$ 's payment schedule is $c_{i}(x) \geq 0(i \in L)$ or $c_{i}(x)=0$ ( $i \notin$ $L)$. Let $C(x)=\sum c_{i}(x)$. From these, principal $i$ 's utility is

$$
U_{i}=a x_{i}^{0.5}+I_{i}-t_{i}-c_{i}(x)
$$

The agent's utility is assumed to be the weighted sum of the social welfare and payments that he receives. Here, the social welfare is

$$
\sum_{i=1}^{n} u_{i}\left(x_{i}\right)+I-T(x) .
$$

So the agent's utility is

$$
V\left(x_{1}, \ldots, x_{n}\right)=\gamma\left(\sum u_{i}\left(x_{i}\right)+I-T(x)\right)+\sum c_{i}(x)
$$

where $\gamma$ is the weight attached to the social welfare.

We assume that there is no asymmetric information. That is, the agent and the principals have complete information. The timing of the model is as follow: (1) Each principal $i \in L$ simultaneously decides her payment schedule $c_{i}(x)$. (2) The agent decides $x=\left(x_{1}, \ldots, x_{n}\right)$. (3) The utilities of the agent and the principals realize.

\section{TRUTHFUL EQUILIBRIUM}

As mentioned in the introduction, the common agency games have multiple subgame perfect equilibria. In those, truthful equilibria have appealing characteristics and are analyzed by the studies. In this paper, we focus on the truthful equilibrium. For detail on the truthful equilibrium of the common agency models, see [2], [4].

In the truthful equilibria, the shape of each principal's payment schedule is the same to that of her indifference surface. Thus, the equilibria are called truthful. Naturally, the government maximizes his utility given the payment schedules. We denote the truthful equilibrium by $\left(\left\{c_{i}^{T}\right\}_{i \in L} ;\left(x_{1}^{T}, \ldots, x_{n}^{T}\right)\right)$.

As for payment schedules in the truthful equilibrium, from truthfulness,

$$
c_{i}^{T}\left(x, U_{i}^{*}\right) \equiv \min \left[0, \varphi_{i}\left(x, U_{i}^{*}\right)\right]
$$

holds where $u_{i}\left(x_{i}\right)+I_{i}-t_{i}-\varphi_{i}\left(x, U_{i}^{*}\right)=U^{*}$ and $U_{i}^{*}$ is the equilibrium utility level. In the truthful equilibrium, $c_{i}^{T}$ is interest group (principal) $i$ 's best response for any $\left(c_{j}\right)_{j \neq i}$. Moreover, in the truthful equilibrium, we have

$\left(x_{i}^{T}, \ldots, x_{n}^{T}\right)=\operatorname{argmax}\left[\gamma\left(\sum_{i=1}^{n} u_{i}+I-T\right)+\sum_{i \in L} c_{i}^{T}\right]$.

From these,

$$
\begin{aligned}
& \left(x_{i}^{T}, \ldots, x_{n}^{T}\right) \\
& =\underset{i \in L t i}{\operatorname{argmax}}\left[(1+\gamma) \sum_{i \in L} u_{i}\left(x_{i}\right)+\gamma \sum_{j \notin L} u_{j}\left(x_{j}\right)-\gamma T-\right. \\
& =\operatorname{argmax}\left[(1+\gamma) \sum_{i \in L} u_{i}\left(x_{i}\right)+\gamma \sum_{j \notin L} u_{j}\left(x_{j}\right)-\right. \\
& \quad \text { In }+\gamma b k=1 n x k .
\end{aligned}
$$

holds.

\section{PROPERTY OF EQUILIBRIA}

In this section, we examine property of the truthful equilibria. At first, we derive the efficient allocation $\left(x_{1}^{*}, \ldots, x_{n}^{*}\right)$ for comparison. The first order condition is

$$
d u_{i}{ }_{d x_{i}}=0.5 a\left(x_{i}\right)^{-0.5}=b
$$

for each $i \in\{1, \ldots, n\}$. From these, we have

$$
x_{i}^{*}=a^{2} / 4 b^{2} \text {. }
$$

In the efficient allocation, the total amount of goods provided by the government, being denoted by $X^{*}$, is

$$
X^{*}=n x_{i}^{*}=a^{2} n / 4 b^{2} .
$$

Next, we examine the truthful equilibria. If interest group $i$ is in $L$, the first order condition with respect to $x_{i}$ is

$$
d u_{i} /_{d x_{i}}=0.5 a\left(x_{i}\right)^{-0.5}=b^{(l+n \gamma)} /(n+n \gamma)
$$

$(i \in L)$. Hereafter we denote this amount by $x_{L}^{T}$ in the case where $i \in L$. So we have

$$
x_{L}^{T}=a^{2} n^{2}(1+\gamma)^{2} / 4 b^{2}(l+n \gamma)^{2}
$$

From $b(l+n \gamma) /(n+n \gamma)<b$, we have over provision of the public good if the interest group makes lobbying activity. (This is similar to the fact proved by [8].)

If interest group $i$ is not in $L$, the first order condition with respect to $x_{i}$ is 


$$
d u_{i} / d x_{i}=0.5 a\left(x_{i}\right)^{-0.5}=b^{(l+n \gamma)} / n \gamma
$$

$(i \notin L)$. Denoting this amount by $x_{N L}^{T}$, we get

$$
x_{N L}^{T}=a^{2} n^{2} \gamma^{2} / 4 b^{2}(l+n \gamma)^{2} .
$$

From $b(l+n \gamma) / n \gamma>b$, we have under provision of the public good if the interest group does not lobby. (This is also similar to the fact proved by [8]).

From these, in the truthful equilibria, we have over provision as well as under provision. Then we have the following question: How about the total amount?

The total amount is, being denoted by $X^{T}$,

$$
\begin{aligned}
X^{T}=l x_{L}^{T} & +(n-l) x_{N L}^{T} \\
& =a^{2} n^{2}\left(l+2 l \gamma+n \gamma^{2}\right) / 4 b^{2}(l+n \gamma)^{2} .
\end{aligned}
$$

Then, the following facts hold.

Proposition 1.

1) We have $X^{T}=X^{*}$ if $l \in\{0, n\}$.

2) We have $X^{T}>X^{*}$ if $l \in\{1, \ldots, n-1\}$.

Proof: As for the difference between $X^{T}$ and $X^{*}$, we have

$$
X^{T}-X^{*}=a^{2} \ln (n-l) / 4 b^{2}(l+n \gamma)^{2},
$$

and these facts hold. (Q.E.D.)

From (1) in the proposition, the allocation of good provided by the government is efficient if every interest group lobbies or if there is no lobbying activity. This is a similar result to that proved by existing researches. On the other hand, from (2) in the proposition, if there are lobbying activities while some interest group does not lobby, the amount of goods provided by the government is greater than the efficient amount. So the amount of goods is inefficient and the size of the government is large.

Next, we examine the effect of the number of the lobbying interest groups.

\section{Proposition 2.}

1) We have $\partial X^{T} / \partial l>0$ if $l<n \gamma /(1+2 \gamma)$.

2) We have $\partial X^{T} / \partial l<0$ if $l>n \gamma /(1+2 \gamma)$.

Proof: By simple calculation, we get

$$
\partial X^{T} / \partial l=a^{2} n^{2}\{n \gamma-(1+2 \gamma) l\} / 4 b^{2}(l+n \gamma)^{3},
$$

and the facts hold. (Q.E.D.)

For any $\gamma, \gamma /(1+2 \gamma)<1 / 2$ holds. Consider the economy where more than half interest groups make lobbying activity. Assume that the government makes the partial prohibition against lobbying (This means $\Delta l=-\varepsilon$ for some small $\varepsilon>0$ ). Then, from Proposition 2, this prohibition results in the greater amount of goods provided by the government and large government size.

Next we examine the degree of inefficiency. To do so, we define

$$
D=X^{T}-X^{*} / n
$$

as the degree of inefficiency. Then, we have the following results.

Proposition 3.

1) We have $\partial D / \partial a>0$.

2) We have $\partial D / \partial b<0$.

Proof: From

$$
\partial D / \partial a=a l(n-l) / 2 b^{2}(l+n \gamma)^{2}
$$

and

$$
\partial D / \partial b=-a l(n-l) / 2 b^{3}(l+n \gamma)^{2}
$$

we have these facts. (Q.E.D.)

If the interest groups' valuation for the group-specific good becomes high, then $x_{i}^{*}, x_{L}^{T}$, and $x_{N L}^{T}$ increase. In this case, we have

$$
\begin{aligned}
& \partial x_{L}^{T} / \partial a= \\
& \left(a / 2 b^{2}\right)\left(\left(n^{2}+2 n^{2} \gamma+n^{2} \gamma^{2}\right) /\left(l^{2}+2 \ln \gamma+n^{2} \gamma^{2}\right)\right)> \\
& \left(a / 2 b^{2}\right)=\partial x_{i}^{*} / \partial a
\end{aligned}
$$

and

$$
\begin{aligned}
& \partial x_{N L / \partial a}^{T}=\left(a / 2 b^{2}\right)\left(n^{2} \gamma^{2} /\left(l^{2}+2 \ln \gamma+n^{2} \gamma^{2}\right)\right)> \\
& \left(a / 2 b^{2}\right)=\partial x_{i}^{*} / \partial a
\end{aligned}
$$

So, the increase rate of $x_{L}^{T}$ is more than that of $x_{i}^{*}$; the increase rate of $x_{N L}^{T}$ is less than that of $x_{i}^{*}$. Therefore we have the fact in (1) of Proposition 3.

If the marginal cost increases, then $x_{i}^{*}, x_{L}^{T}$, and $x_{N L}^{T}$ decrease. In this case,

$$
\begin{aligned}
& \partial x_{L}^{T} / \partial b= \\
& -\left(a^{2} / 2 b^{3}\right)\left(\left(n^{2}+2 n^{2} \gamma+n^{2} \gamma^{2}\right) /\left(l^{2}+2 \ln \gamma+n^{2} \gamma^{2}\right)\right)< \\
& -\left(a^{2} / 2 b^{3}\right)=\partial x_{i}^{*} / \partial b
\end{aligned}
$$


and

$$
\begin{aligned}
& \partial x_{N L}^{T} / \partial b=-\left(a^{2} / 2 b^{3}\right)\left(n^{2} \gamma^{2} /\left(l^{2}+2 \ln \gamma+n^{2} \gamma^{2}\right)\right)> \\
& -\left(a^{2} / 2 b^{3}\right)={ }^{\partial x_{i}^{*}} / \partial b .
\end{aligned}
$$

So, the decrease rate of $x_{L}^{T}$ is more than that of $x_{i}^{*}$; the decrease rate of $x_{N L}^{T}$ is less than that of $x_{i}^{*}$. Therefore we have the fact in (2) of Proposition 3.

Next, we examine the influence of the size of the society on inefficiency.

Proposition 4.

1) We have $\partial D / \partial n>0$ if $l>n \gamma /(1+2 \gamma)$.

2) We have $\partial D / \partial n<0$ if $l<n \gamma /(1+2 \gamma)$.

Proof: From

$$
\partial \mathrm{D} / \partial n=a^{2} l\{(1+2 \gamma)-n \gamma\} / 4 b^{2}(l+n \gamma)^{3},
$$

we have these facts. (Q.E.D.)

If the set of lobbying interest groups is large, then the growth of the society confounds efficiency. In contrast, if the set of lobbying interest groups is small, then the growth of the society alleviates inefficiency.

In the above proposition, we assume that the number of the lobbying interest groups is constant even though the society becomes large. Let $l=e(n) \cdot n$. Then we have the follows.

Proposition 5.

1) We have $\partial D / \partial n=0$ if $d e / d n=0$.

2) We have $\partial D / \partial n>0$ if $d e / d n<0$ and $e>$ $\gamma /(1+2 \gamma)$

3) We have $\partial D / \partial n<0$ if $d e / d n<0$ and $e<$ $\gamma /(1+2 \gamma)$

4) We have $\partial D / \partial n>0$ if $d e / d n>0$ and $e<$ $\gamma /(1+2 \gamma)$

5) We have $\partial D / \partial n<0$ if $d e / d n>0$ and $e>$ $\gamma /(1+2 \gamma)$

Proof: From

$\partial D / \partial n=\left[a^{2}\{\gamma-(1+2 \gamma) e\} / 4 b^{2}(e+\gamma)^{3}\right](d e / d n)$,

we have these facts. (Q.E.D.)

If the ratio of the set of lobbying interest groups to the society is constant, then the growth of the society has no effect on efficiency. If the ratio decreases as the society grows, then the growth of the society has the similar effect to that in Proposition 4. Conversely, the ratio increases as the society grows, the growth of the society has opposite effect.

\section{CONCLUDING REMARKS}

In many studies analyzing policy decision, the common agency models are adopted. In addition, they focus on the property of the truthful equilibria. It has already been proved that the public policy is efficient in the truthful equilibrium of the common agency models. But, if some interest group does not make lobbying activity, the allocation is not efficient from the viewpoint of the social welfare. In this paper, we analyze such situations.

We prove that the amount of goods provided by the government is greater than that in the efficient allocation if some interest group does not make lobbying activity. That is, the government size is greater. Moreover, we prove that the partial prohibition against lobby enlarges the government size in some cases.

In addition, if the interest groups' valuation for the group-specific good becomes high, then the allocation becomes to be more inefficient, and if the marginal cost decreases, then the allocation also becomes to be more inefficient. The effect of the size of the society depends on circumstances and is complex.

Last, based on these results, we present an interpretation of the success and failure of Japanese industrial policies. Someone attributes Japanese success after the Second World War to industrial policies. (See, for example [7].) And many find the 'iron triangle' behind the decision process of policies in Japanese government. The triangle unites the mutual interests of industries, politicians and bureaucrats. In Japan, the bureaucracy has many original bureaus and each original bureau is in charge of some industry. So many industries can make influence on policy decision through the triangle (see [9], [10]).

As proved in this paper, if the set of lobbying interest groups coincides (almost) entirely with the set of the interest groups, the policy is (fairly) efficient. So if the set of original bureaus covers the set of the industries, the (fairly) efficient policy results. This partially explains Japanese economic success after the Second World War.

As time passes, however, the structure of the industries changes drastically while the structure of bureaucracy changes a little. Then, the gap between the two sets emerges and grows. Especially, Japan faced such a drastic change in the structure of industries after 1980's. The gap, as proved in this paper, leads to inefficiency of the policy and increase of the government expenditure. This partially explains Japanese economic failure after the economic bubble burst in Japan.

\section{ACKNOWLEDGMENT}

I would like to thank Masahiko Asano, Midori Hirokawa, Takashi Tomizaki and Jun-ichiro Wada for their comments.

\section{REFERENCES}

[1] D. P. Baron and A. V. Hirsch "Common agency lobbying over coalitions and policy," Economic Theory, vol. 49, pp. 639-681, 2012.

[2] B. D. Bernheim and M. Whinston, "Menu cost, resource allocation, and economic influence," Quarterly Journal of Economics, vol. 101, pp. 1-31, 1986.

[3] M. Bordignon, L. Colombo, and U. Galmarini, "Fiscal federalism and lobbying," Journal of Public Economics, vol. 92, pp. 2288-2301. 
[4] A. Dixit, G. Grossman, and E. Helpman, "Common agency and coordination: General theory and application to government policy making," Journal of Political Economy, vol. 105, pp. 752-769, 1997.

[5] M. Felgenhauer, "Policy bias equivalence under common agency," Journal of Economics, vol. 90, pp. 295-312, 2007.

[6] G. Grossman and E. Helpman, "Protection for sale," American Economic Review, vol. 84, pp. 833-850, 1994.

[7] C. A. Johnson, MITI and the Japanese Miracle: The Growth of Industrial Policy, pp. 1925-1975, Stanford University Press, 1982.

[8] T. Persson, "Economic policy and special interest politics," Economic Journal, vol. 108, pp. 310-327, 1998

[9] M. Aoki, Toward a Comparative Institutional Analysis, Cambridge: MIT Press, 2001.

[10] M. Okuno-Fujiwara, "Toward a comparative institutional analysis of the government-business relationship," in M. Aoki, H. Kim and M. Okuno-Fujiwara (eds.), The Role of Government in East Asian
Economic Development: Comparative Institutional Analysis, Oxforf University Press, 1997, pp. 373-406.

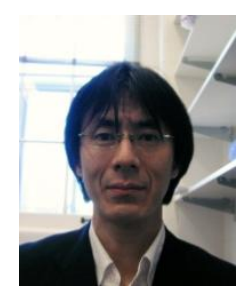

Tetsuro Okazaki received Bachelor of Economics and Master of Economics from Keio University, Japan, in 1988 and 1990 . He is currently a professor at Chiba University of Commerce. 